\title{
The Multidirectional Effect of Nitrite Oxide the Longitudinal and Circular Smooth Muscle Layers of the Wall of the Stomach and Duodenum
}

\section{Trubitsyna IE ${ }^{1 *}$, Abdulatipova ZM'ㅜ, Petrakov AV1, Efremov LI ${ }^{1}$, Smirnova $\mathrm{AV}^{3}$, Tarasova $\mathrm{TV}^{2}$, Papysheva $\mathrm{LD}^{1}$ Vasilyeva $\mathrm{IS}^{4}$, Vasilyeva $\mathrm{VV}^{5}$ and Ruchkina IN ${ }^{1}$}

${ }^{1}$ Moscow Clinical Scientific and Practical Center Named After A.S. Loginova, MKSC Named After A.S. Loginova, Moscow, Russia

${ }^{2}$ Mordovia State University, N.P. Ogareva, Saransk Historical and Sociological Institute, Federal State Budgetary Educational Institution of Higher Education "National Research", Russia

${ }^{3}$ Federal State Budgetary Institution "National Medical Research Oncological Center Named After N.N. Blokhin" of the Ministry of Health of Russia (FSBI National Medical Research Oncological Center Named After N.N. Blokhin of the Ministry of Health of Russia), Russia

${ }^{4}$ Federal State Autonomous Educational Institution of Higher Education I.M. Sechenov First Moscow State Medical University of the Ministry of Health of the Russian Federation (Sechenov University), Moscow, Russia

${ }^{4}$ Candidate of Medical Sciences, Associate Professor, Associate Professor of the Department of Ambulance and Emergency Aid. Moscow Regional Research Clinical Institute. M.F. Vladimirsky, Moscow

*Corresponding Author: Trubitsyna IE, Moscow Clinical Scientific and Practical Center Named After A.S. Loginova, MKSC Named After A.S. Loginova, Moscow, Russia.
Received: November 15, 2021

Published: December 10, 2021

(C) All rights are reserved by Trubitsyna IE., et al.

\section{Abstract}

In the article, conducting experimental studies on white rats of the Wistar line, we considered the effect of NO, as a mediator of inflammation in experimental colon ulcers, on smooth muscles (GM) of the stomach (G), duodenum (D) and colon (C). The experiments were carried out on white rats, of both sexes, weighing 180-220 g (average weight $200 \mathrm{~g}$ ). The keeping of animals in the vivarium was in accordance with the sanitary rules. All experiments were carried out in accordance with the rules of humane treatment of animals. All manipulations were performed under general anesthesia in compliance with aseptic and antiseptic requirements.

To determine the level of NO in the blood serum, the nitrite/nitrate (NOx) method was used. Experimental colitis was induced by oral administration of 5\% Dextran sodium sulfate (DSS) polymer solution of dactran sodium sulfate. To inhibit NO synthase, the animals were injected intraperitoneally with $1.0 \mathrm{ml}$ of a $1 \%$ aqueous solution of Methylene coeruleus. a high level of NO content, due to the increased activity of the inducible form of NO-synthase, has not only a toxic effect on the mucous membrane of the colon, with a simultaneous relaxing effect on the circular and contraction of the longitudinal layer of the GM G, pyloric canal and D. The nature of the effect on all these parts of the gastroduodenal zone has a different degree of relaxation, which is the result of specific tissue homeostasis.

Keywords: NO; Stomach; Duodenum; Smooth Muscles

Smooth muscle cells (GM) of the stomach and intestines are subject to regulation by their own neuroendocrine and autonomic nervous systems [1,2]. The musculature consists of the outer longitudinal and inner circular layers of muscles, which makes it pos- sible to shorten and reduce the lumen of the hollow organs of the gastrointestinal tract. The contraction of the smooth muscles of the gastrointestinal tract occurs as a result of the activity of the rhythm sensor and myogenic mechanisms. 
GM can be in a reduced state for a long time without signs of fatigue. By the nature of the effect on external stimuli, smooth muscles can be divided into three groups:

- Muscles that contract in response to external stimulation and do not have spontaneous activity (pilomotor)

- Muscles with spontaneous rhythmic activity (muscles of the gastrointestinal tract). They respond to irritation on an allor-nothing basis.

- Muscles occupying an intermediate position between the first and second groups (circular intestinal muscles).

The regulation of GM contractions is complex multilevel [2], which is carried out by myogenic and neuro-humoral mechanisms, but the main role belongs to the nervous system. In the intestinal nervous system, excluding the stomach, there are from 107 to $10^{8}$ nerve cells - almost the same as in the spinal cord.

- $\quad$ Myogenic mechanisms - the basis is the property of GM to spontaneously contract and respond to irritation by contraction. This is an innate property of GM. The frequency of rhythmic contractions is set by the rhythm sensors and these rhythmic contractions and the activity of the sensors do not depend on the nervous system, but depends on the level of the membrane potential, metabolism, temperature, the magnitude of the peak potential discharges, etc. nervous system.

- The intramural nervous system consists of several plexuses:

- $\quad$ Myenteric (Auerbach), it lies between the circular and longitudinal muscle layers;

- $\quad$ Deep intermuscular (Vorobyevo);

- $\quad$ Submucosal (Meissner's);

These plexuses closely interact with each other, providing the closure of local reflex arcs, regulating the functional and motor activity of the digestive organs. In addition, more than one neurotransmitter usually works in the enteric nervous system and each neurotransmitter has its own receptor. Peristalsis is an internal self-sustaining function that does not stop even in isolated segments of the intestine. This is a complex movement process, when a wave of muscle relaxation is followed by a wave of contraction.
The longitudinal layer is a rhythm sensor for the circular muscle layer, but the circular and longitudinal muscles in the final effect can be independent or opposite. Relaxation of the longitudinal muscle layer is carried out by non-adrenergic mediation, but active relaxation is due to the activation of adrenergic inhibitory mechanisms and is not eliminated by all known blockers of adrenergic and cholinergic innervation. The contraction of the circular and longitudinal muscles has a common non-choliergic initial pathway. Potentiation of the effect of target cells (myocytes) occurs when two or more substances act on them together, triggering different (non-competing) intracellular metabolic processes. These can be derivatives of amino acids, peptides, Ax, NO and other neurotransmitters. Contraction occurs when the Ax muscarinic receptors are stimulated on the surface of the muscle cell, and NO (nitric oxide) is the main mediator of relaxation after contraction.

Where exactly NO is formed - in nerve endings or smooth myocytes - is unclear. In addition to endotheliocytes and neurons, the constitutive form of NO synthase was also found in myocytes [3]. The presence of NO in the peripheral nervous system is necessary for signal transmission in cholinergic synapses formed by postganglionic endings of the parasympathetic nervous system on smooth myocytes of internal organs. The release of acetylcholine in these synapses is accompanied by an increase in the concentration of NO in the synaptic region. As you can see, this is an interdependent process, an oscillatory response.

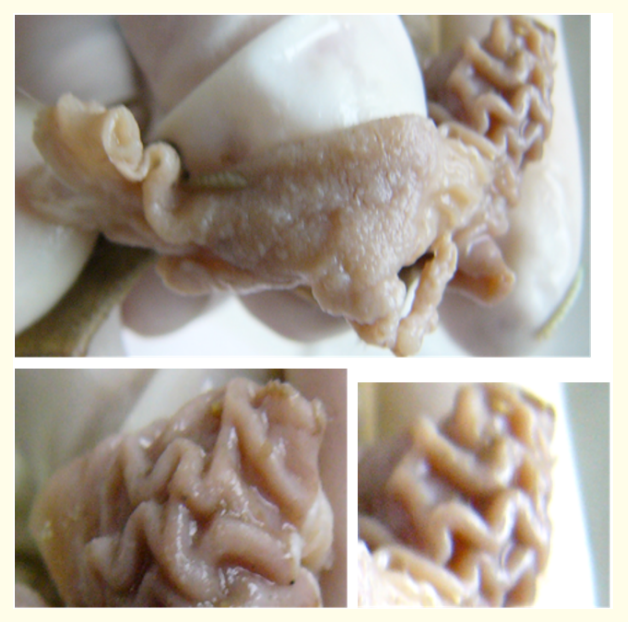

Figure 1: Rats with experimental DSS-induced colitis without methylene blue administration. 
Under physiological conditions, NO synthase synthesizes a picomolar amount of NO, which is quite sufficient to ensure the vital activity of an organ, tissue, and cell. It takes part in the regulation of vasodilation, electrolyte secretion, and a decrease in platelet aggregation. In pathological conditions (shock, inflammation, etc.), an inducible form of NO synthase synthesizes a micromolar amount of NO [4], which can lead not only to a cytotoxic effect, but also to disrupt the relationship between active substances involved in the contraction and relaxation of smooth muscles.
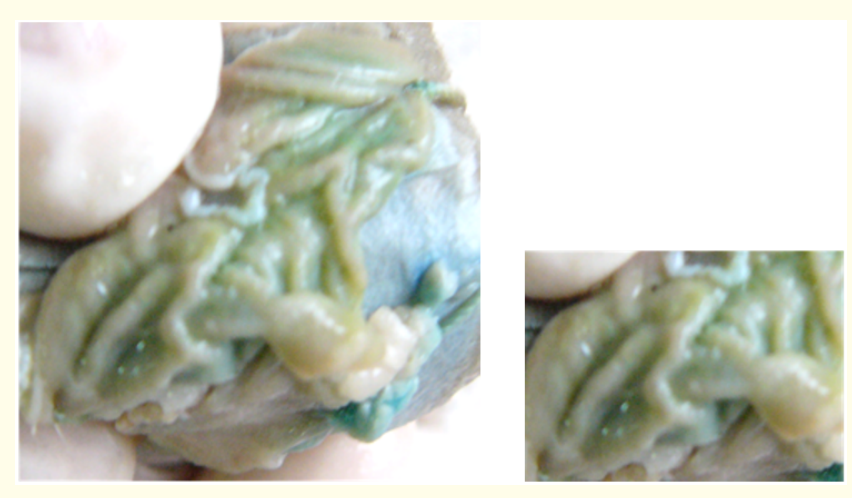

Figure 1: Rats with experimental colitis caused by DSS with the introduction of methylene blue.

\begin{tabular}{|c|c|c|}
\hline & \multicolumn{2}{|c|}{ Level NOx, mkmol/l } \\
\hline DSS & $\begin{array}{c}\text { Without the intro- } \\
\text { duction of a NOx } \\
\text { inhibitor }\end{array}$ & $\begin{array}{c}\text { Introduction } \\
\text { of methylene } \\
\text { blue }\end{array}$ \\
\hline DSS (n=10+10) & $57,9 \pm 4,37$ & M \pm m \\
\hline In intact animals $(n=6)$ & \multicolumn{2}{|c|}{$30,2 \pm 2,5$} \\
\hline
\end{tabular}

Table 1: Level of stable no metabolites in rats NOx level, micromole/l.

The aim of our work is to reveal the participation of NO in the relaxation of GM in experimental colitis in rats.

\section{Materials and Methods, Discussion and Conclusion}

The experiments were carried out on white rats, of both sexes, weighing 180-220 g (average weight $200 \mathrm{~g}$ ). The keeping of ani- mals in the vivarium was in accordance with the sanitary rules. All experiments were carried out in accordance with the rules.

The method of determination of nitrite/nitrate (NOx) was used to determine the level of NO in blood serum [2]. Experimental colitis was caused by oral administration of a $5 \%$ solution of the polymer dactran sodium sulfate Dactran sodium sulfate (DSS). To inhibit NO synthase, $1.0 \mathrm{ml}$ of $1 \%$ aqueous solution of Methyleni coeruelei, which is a non-specific inhibitor of inducible and constitutional forms of the enzyme, was administered intraperitoneally to animals.

The animals were divided into four groups. The first experimental - 01 (10 animals) - instead of water as a drink, a 5\% solution of DSS + an intravenous injection of $1.0 \mathrm{ml}$ of saline solution was obtained.

The second $-\mathrm{O}_{2}$ (10 animals) instead of water, DSS solution + I/w introduction of 1.0 methylene blue; the third K1 (5 animals) the control group normal diet and drinking I/w introduction of 1.0 $\mathrm{ml}$ of saline solution; the fourth K2 (5 animals) - normal diet and drinking $+\mathrm{I} / \mathrm{w}$ introduction of $1.0 \mathrm{ml}$ of methylene blue. The duration of the study is 7 days. On the seventh day, the animals were slaughtered under ether anesthesia. The stomach and duodenum were extracted, cut and the mucous membrane was revised. In the first group, when the stomach was opened, attention was drawn to the unusual arrangement of the folds. There are no longitudinal folds, only transverse folds are present, the gastric mucosa is "gathered" (Figure 1). This is possible if the circular muscles are relaxed and the longitudinal muscles are contracted. Priloroduodenal zone - the pyloric canal and proximal duodenum are dilated (Figure 1). The distal part of the duodenum - the longitudinal muscles are contracted, the circular muscles are relaxed, but to a lesser extent than in the proximal part, the effect of "gathering" is observed. In this group, the concentration of NO is twice the reference value (Table 1).

Thus, a high level of NO, due to the increased activity of the inducible form of NO synthase, has not only a toxic effect on the mucous membrane of the colon, but also a relaxing effect on the circular layer of smooth muscles of the stomach, pyloric canal, and duodenum. The nature of the impact on all these parts of the gastroduodenal zone has a different degree of relaxation, which is the result of specific tissue homeostasis. 


\section{Bibliography}

1. Zverev AA., et al. "Physiology of muscles: teaching aid for students. higher. educational institutions". Kazan, Kazan Federal University (2016): 41.

2. KV Sudakov., et al. "Electronic edition based on: Human Physiology. Atlas of dynamic schemes: textbook". ed. K. V. Sudakova. $2^{\text {nd }}$ ed., Rev. and add. GEOTAR-Media (2015): 416.

3. Lazebnik LB., et al. "The role of nitric oxide (NO) in the etiopathogenesis of some diseases of the digestive system". Experimental and Clinical Gastroenterology 2 (2005): 4-12.

4. Baryshnikov EN., et al. "Effect of corticosteroids on nitric oxide production in patients with inflammatory bowel diseases". VII Congress of the Scientific Society of Gastroenterologists of Russia, dedicated to the $40^{\text {th }}$ anniversary of the All-Union Scientific Research Institute of Gastroenterology - Central Research Institute gastroenterology 273-274.

\section{Assets from publication with us}

- Prompt Acknowledgement after receiving the article

- Thorough Double blinded peer review

- Rapid Publication

- Issue of Publication Certificate

- High visibility of your Published work

Website: www.actascientific.com/

Submit Article: www.actascientific.com/submission.php

Email us: editor@actascientific.com

Contact us: +919182824667 